\title{
Una narrativa para la diversidad: representaciones de la comunidad afrodescendiente desde la literatura infantil
}

\author{
Valeria Angulo Tarapues \\ DAYANA Rodríguez BERnAL
}

Paola Velandia Vega ${ }^{\mathrm{T}}$

\section{Introducción}

En el presente artículo se aborda la manera en que son representadas las temáticas afro en los cuentos La muñeca negra de Mary Grueso (2011) y Niña bonita de Ana María Machado (1996). Lo anterior se da con el propósito de hacer un análisis desde las categorías de lo afrodescendiente o afrocolombiano en las formas de expresión planteadas desde estos cuentos, ya que son estrategias que permiten tener un conocimiento cultural, social y obtener reconocimiento de la identidad de manera creativa y dinámica. En este sentido, se trata de mostrar las representaciones sociales que se transmiten a través de la literatura en los niños, quienes son una parte fundamental de la sociedad y que por lo tanto deben ser formados en valores en los cuales se aprecie y valore la diferencia. Este concepto es importante, pues es desde allí donde se pueden tratar y evitar hechos como la discriminación y

1 Estudiantes de la Facultad de Comunicación Social de la Universidad Santo Tomás. 
la exclusión que se han presentado continuamente desde hace años en diversas sociedades y clases sociales.

Es importante resaltar que el lenguaje es un aliado importante en estos espacios pues, como manera de comunicación e información, influye en la comprensión o construcción de la realidad, es decir, son reflejo de la sociedad ya que constituyen formas de pensamiento y conceptos que se manifiestan en la vida cotidiana.

Para responder a la pregunta planteada tomamos la propuesta de análisis de las estrategias del lenguaje e imágenes o ilustraciones, pues es en el lenguaje en donde se ejerce el dominio de intereses, recursos y estrategias que tienen como fin mantener el poder; asimismo es necesario destacar que las imágenes e ilustraciones son indispensables en la literatura infantil pues da cuenta de la recepción eficaz en los niños al sentirse identificados con los mismos. Es por esto que las estrategias del lenguaje que se emplearon para demostrar las representaciones sociales afrodescendientes son la legitimación ${ }^{2}$ y naturalización ${ }^{3}$. Además se observará la manera en que, dentro del cuento, son aplicadas la metáfora y la hipérbole ya que este tipo de elementos orientan la acción social o la hacen más persuasiva. Hay que destacar que los recursos literarios y discursivos son utilizados para transmitir los diferentes conceptos y percepciones.

Para el desarrollo de este artículo realizamos una revisión bibliográfica sobre los estudios que se han realizado en torno a la literatura afrodescendiente, pues son fuentes en las cuales perduran narrativas que facilitan la comprensión de distintas transformaciones y las dificultades de los temas relacionados a lo afrodescendiente o afrocolombiano.

En primer lugar se analizó la investigación del libro De sol a sol: génesis, transformación y presencia de negros en Colombia (Arocha y Friedemann, 1988) en el cual, los autores se enfocan en la transformación de las relaciones de los pueblos afroamericanos.

2 Fenómeno sociodiscursivo mediante el cual un sector de la sociedad busca aprobación moral de su grupo como respuesta o previsión a acusaciones que le ponen en riesgo (Van Dijik, 1980).

3 Normaliza un fenómeno social Van Dijk (1980). 
A lo largo del texto se tratan diversos temas que permiten entender la historia de los negros en Colombia refiriéndose a la manera en que las prácticas esclavas generaron la separación social y cultural de los afrodescendientes. Fue así como esta comunidad fue forjando nuevos mundos en los que se creó una reflexión sobre la manera en que han sido negados e invisibilizados los aportes de estos grupos en la formación de la nación colombiana. Sin embargo, pasados muchos años para el reconocimiento de esta población todavía se ven ignoradas en escenarios como la literatura y la lengua. Y aunque la danza y la música son las expresiones artísticas más exaltadas cuando se habla de lo afrocolombiano, se hace un llamado a la valoración intelectual, social e histórica de la comunidad afrocolombiana.

Arocha y Friedemann (1988) también exponen que en varias formas de narración que son utilizadas por diversos autores, aún se desconoce la ascendencia africana debido a que las maneras de manifestar y mencionar las ideas se hacen a partir de las lenguas que se podrían mencionar o considerar oficiales como lo son el español, el inglés y el francés, dejando de lado vocablos que podrían expresar mejor las vivencias de la población negra, e incluso afectan en la consolidación de la identidad que se puede simbolizar o expresar de otras maneras.

Otro de los autores que elegimos para la identificación de las narrativas presentadas en los cuentos fue Manuel Zapata Olivella (1997) quien menciona en su texto La rebelión de los genes los problemas que hay frente a la identidad de los escritores negros, en el cual la estructura del lenguaje se convierte en un elemento opresor. Asimismo, considera necesario que haya una modificación de esas estructuras y que se debe crear un lenguaje que exprese nuevas imágenes y acentos con plena libertad. Del mismo modo, el autor destaca que "los complejos lingüísticos nos llevan a preocuparnos más por el superestrato colonizador, amputado y enmascarador de las lenguas conquistadas y poco por el substrato rebelde, libertario y connotativo de nuestras vivencias" (Zapata, 1997, p.12).

Esa preocupación y limitación no ha permitido que se cuestione cuál es la identidad cultural que se está ignorando, y son esas comunidades tan diversas las que muchas veces no se sienten identificadas con lo que se expone de ellas. De ahí la insistencia en la importancia 
de la literatura infantil, pues además de ser una apuesta para la creatividad y el conocimiento, es también una alternativa para la formación de actitudes y valores frente a ese otro que es distinto. Es así como por medio de lenguajes dinámicos que se puede ayudar a explorar una realidad que no esté simplificada y de esta manera les ayuden a conocer nuevos protagonistas.

Por ello podemos resaltar que los cuentos Niña bonita y La muñeca negra intentan retratar un sistema cultural de unas comunidades que tienen sus propios conocimientos y tradiciones, proponiendo el reconocimiento de otras identidades, que están dirigidas principalmente a las niñas y niños, en las cuales se evidencia que la literatura es una alternativa para mostrar que hay una multiculturalidad. Asimismo busca mostrar un reconocimiento a estas comunidades, desde algunos de los personajes, paisajes y lugares que se describen y proponen en estos escritos.

A continuación se darán a conocer los análisis realizados a los libros seleccionados:

\section{Niña bonita}

Dentro de esta historia escrita por la brasileña Ana María Machado se presenta un variado uso de la metáfora, con el fin de comparar, ejemplificar o hacer referencia a algo o alguien con el fin de catalogarlo dentro de un esquema específico. Hay que tener en cuenta que el uso de este recurso hace parte de la cotidianidad y por lo tanto el lenguaje está impregnado de ella y de forma inconsciente, en su mayoría, es apropiada y hablada por la gente, y es dentro de este esquema que las personas actúan y hablan. Lo anterior se refleja en frases como:

Había una vez una niña bonita, bien bonita. Tenía los ojos como dos aceitunas negras, lisas y muy brillantes. Su cabello era rizado y negro, muy negro, como hecho de finas hebras de la noche. Su piel era oscura y lustrosa, más suave que la piel de la pantera cuando juega en la lluvia. (p.1)

(...) Y la niña bonita terminaba pareciendo una princesa de las Tierras de África o un hada del Reino de la Luna. (p.2) 
No tuvo que buscar mucho. Muy pronto, encontró una coneja oscura como la noche que hallaba a ese conejo blanco muy simpático. (p.4)

Es importante resaltar que la forma de hacer uso de las metáforas no trata de mandar una nueva percepción o concepto, más bien lo complementa sin ser despectivo. En este sentido, las palabras transmiten una experiencia para que unos conceptos puedan ser entendidos teniendo en cuenta otros. Es evidente que, más que reforzar una creencia social de discriminación con la metáfora, la autora trata de incluir un nuevo marco de representación teniendo en cuenta el contexto en el cual se desarrolla la historia y sobretodo los protagonistas que la crean.

También, en la mayoría de apartados del cuento, se evidencia la estrategia de legitimación que tiene como fin transmitir la aprobación moral, frente a algo o alguien. En este caso, se trata de hacer una oposición frente a lo que otros comúnmente dicen, ya que la autora trata, mediante el personaje de la niña, evidenciar una estructura en la cual ella representa la belleza y ese elemento es el que permite que el texto se aleje de los cánones que suelen ser trasmitidos en los medios de masas. Lo anterior se ejemplifica con los siguientes apartados:

El conejo pensaba que la niña bonita era la persona más linda que habia visto en toda su vida. Y decía: -cuando yo me case, quiero tener una hija negrita y bonita, tan linda como ella...(p.9)

Cuando se mejoró, regresó adonde la niña y le preguntó una vez más: -Niña bonita, niña bonita, ¿cuál es tu secreto para ser tan negrita? La niña no sabía y ya iba a ponerse a inventar algo de unos frijoles negros, cuando su madre, que era una mulata linda y risueña, dijo: -Ningún secreto. Encantos de una abuela negra que ella tenía. (p. 12)

Por ello, la aceptación que pretende lograr la autora trasciende de un aspecto neutral y opta por elementos positivos que puedan traer algo de inclusión y no de separación y es por eso que la relación y la percepción que tiene el conejo blanco de ella es clara y amable. Además, durante el desarrollo de la historia no se muestran relaciones de poder o dominación entre los personajes sino que por el contrario, se percibe una relación cordial y de admiración. 
Asimismo, tampoco se hace una observación negativa sobre "los otros" y positiva sobre "nosotros" sino que ambos son tratados como iguales, incluso en términos equitativos; por este motivo, tanto la niña como el conejo tienen voz dentro de toda la historia.

\section{La muñeca negra}

La poeta, narradora y maestra Mary Grueso, es una de las reconocidas escritoras afrodescendientes que encaminan sus textos al aprendizaje por medio de la literatura. Es importante añadir que la autora escribió este texto con el objetivo de llevar historias en donde la comunidad afrodescendiente, en este caso niños, se sientan representados y reflejados, que de alguna u otra forma los lectores se sientan motivados y vean un poco de literatura afrodescendiente en las aulas de clase.

En esta historia se puede evidenciar el manejo de las metáforas que realiza en un sentido libre y no tan literal al referenciar desde un comienzo que sus experiencias de pequeña con respecto a las muñecas se muestran en el cuento, ya que desde ese aspecto trae su realidad a la infancia de ahora ejemplificando sucesos como el de la existencia de la muñeca negra en épocas atrás. Asimismo, hace referencia a que las niñas afrodescendientes no poseían muñecas negras por el hecho de que no existían y por ello narra su historia reflejando la utilización de las 'pachas' de plátano o tela oscura para poder conseguirla.

Tú siempre me dices muñeca y como soy negra, soy una muñeca negra, entonces yo creo que han hecho muñecas negras, como yo. -No bija, no puedo regalarte una muñeca negra, porque nunca la he visto. (p.7)

Esta es una de las frases que evidencia la referencia que realiza de su realidad pues nunca obtuvo una muñeca negra porque no existían.

Pero mamá... yo quiero una muñeca, que sea de mi color, que tenga los ojos de chocolate y la piel como un carbón. (p.7)

Una muestra de la frase anterior es el sentido figurado que utiliza la autora ya que describe elementos que reflejan y asemejan a lo que realmente quiere decir la niña, una muñeca de color y también se comprende mediante la asociación de elementos. 
La legitimación en este cuento se da indirectamente por medio de la validación discursiva que realiza el padre de la niña por el motivo por los cuales del cielo no llegaba una muñeca.

Papá me puedes comprar una muñeca negra, como yo. Le dije a mi mamá y no me la compró, me dijo que se la pidiera a Dios ¿Cómo que se la pidas a Dios? Si muñeca negra del cielo no manda Dios. Buscá tu pedazo de trapo y hacé tu muñeca vos. (p.9)

Es importante resaltar que el cuento, en un principio, narraba cosas que hacían ver las acciones de la niña como naturales como el siguiente fragmento:

El tiempo fue pasando y la niña fue creciendo, cuando ya estuvo más grandecita, la mamá le regalaba las "pachas" de plátano para que jugara con ellas, como muñecas, ya que las niñas negras no tenían muñecas para jugar, había que poner la "pacha" a madurar, en "botija" de maiz, para poderla utilizar. (p.15)

Al contrario que el otro texto, este no muestra contraste entre población que no es afrodescendiente y la que sí lo es. Solamente muestra a la comunidad en un escenario de pobreza y a la vez de discriminación por parte de elementos tales como los juguetes de muñeca negra que las niñas afro no tenían para jugar. También se evidencia que la autora mediante su escrito intenta mostrar la realidad que se vivía hace aproximadamente 35 años y la manera en que la población infantil afrodescendiente vivía.

Así como el texto de Ana María Machado, este cuento no tiene ninguna relación de dominación pues todos los personajes que allí aparecen son de la comunidad afrodescendiente.

\section{Conclusiones}

A partir de los resultados expuestos, una de las conclusiones que planteamos está relacionada a los procesos de etnización que se proponen desde los cuentos escogidos, ya que los lugares y las maneras como se enuncian las comunidades afrodescendientes varían según el lugar de procedencia de las autoras. 
Es el caso de Ana María Machado, periodista, profesora y escritora brasileña, a quién la crítica la considera una de las mejores escritoras dentro de la literatura contemporánea. Sin embargo, su acercamiento a las comunidades afrodescendientes se da desde una mirada externa, ya que no se reconoce como parte de estos grupos, y por lo tanto, su propuesta no ahonda en las características propias como el lenguaje, prácticas y costumbres que forman a la cultura afrobrasileña.

Por otro lado se encuentra la experiencia narrada por Mary Grueso, escritora, profesora y narradora oral, quien hace parte de la comunidad afrocolombiana, y quien ha llevado a cabo varios procesos para lograr el reconocimiento y rescatar la importancia de la herencia africana en Colombia, pues la autora desde su autoidentificación tiene la intención de mostrarle al mundo quienes son los afrocolombianos, y de esta manera entregar en sus escritos el legado ancestral que deberían conocer los niños afrodescendientes, para que la diversidad fortalezca un país pluriétnico como Colombia.

Otro hallazgo dentro del análisis realizado está relacionado a los procesos de autoidentificación que tienen las protagonistas en los cuentos. En el cuento Niña bonita, se hace un relato en el que la protagonista debe contestar algunas preguntas relacionadas a su color de piel y plantear algunas propuestas, hasta que finalmente se habla de una herencia familiar que viene dada por su abuela. Es interesante identificar el uso de metáforas pues en el intento de dar respuesta a los cuestionamientos hechos por el conejo blanco, la niña se compara con la noche, el café, las aceitunas y demás, las cuales son nociones expuestas que tratan de dar una orientación a los niños que están en un proceso de reconocimiento e identificación.

Desde el cuento La muñeca negra, la narración tiene como objetivo mostrar cómo la protagonista se reconoce a partir de una muñeca que su mamá le confeccionó, pues la trama del cuento es que no existen juguetes del mismo color de piel de la niña, es cuando su mamá le menciona que no puede regalarle una muñeca así, pues nunca las ha visto. Desde este proceso se evidencia la autoidentificación, expresado en el momento que la niña recibe una muñeca de trapo confeccionada por su madre y exclama con emoción que por fin tiene una muñeca oscurita como ella. 
UNA NARRATIVA PARA LA DIVERSIDAD: REPRESENTACIONES DE LA COMUNIDAD AFRODESCENDIENTE DESDE LA LITERATURA INFANTIL

En este proceso es importante resaltar las ilustraciones que hacen parte de los cuentos, los cuales logran reforzar las ideas que se presentan en ellos.

Imagen 1. Niña bonita. Por Ana María Machado (1996).

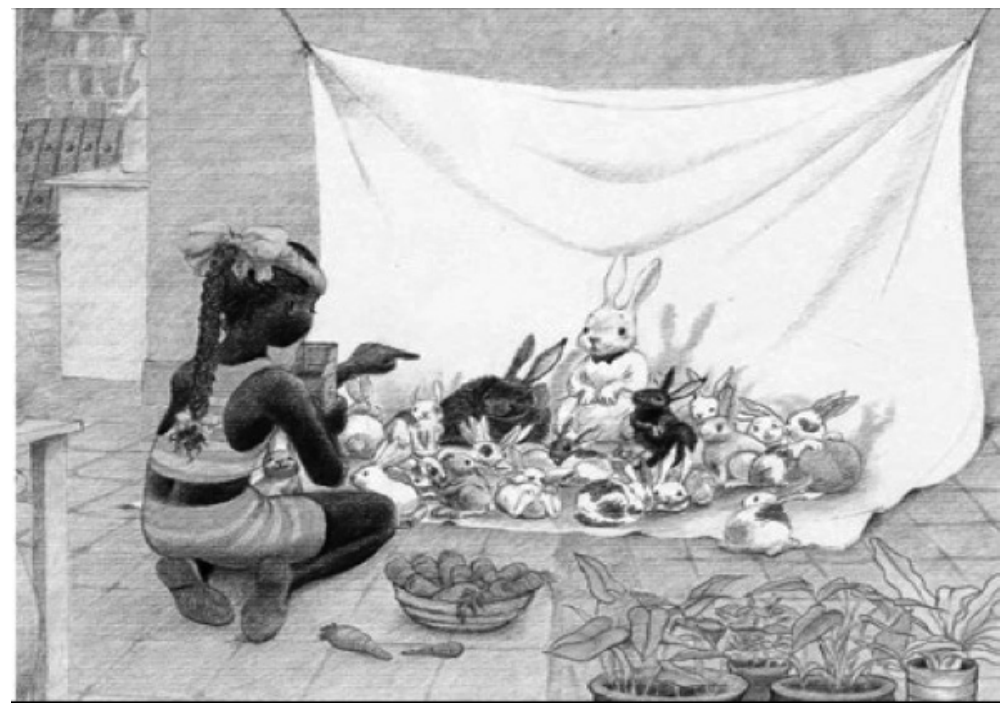

Imagen 2. Niña bonita. Por Ana María Machado (1996).

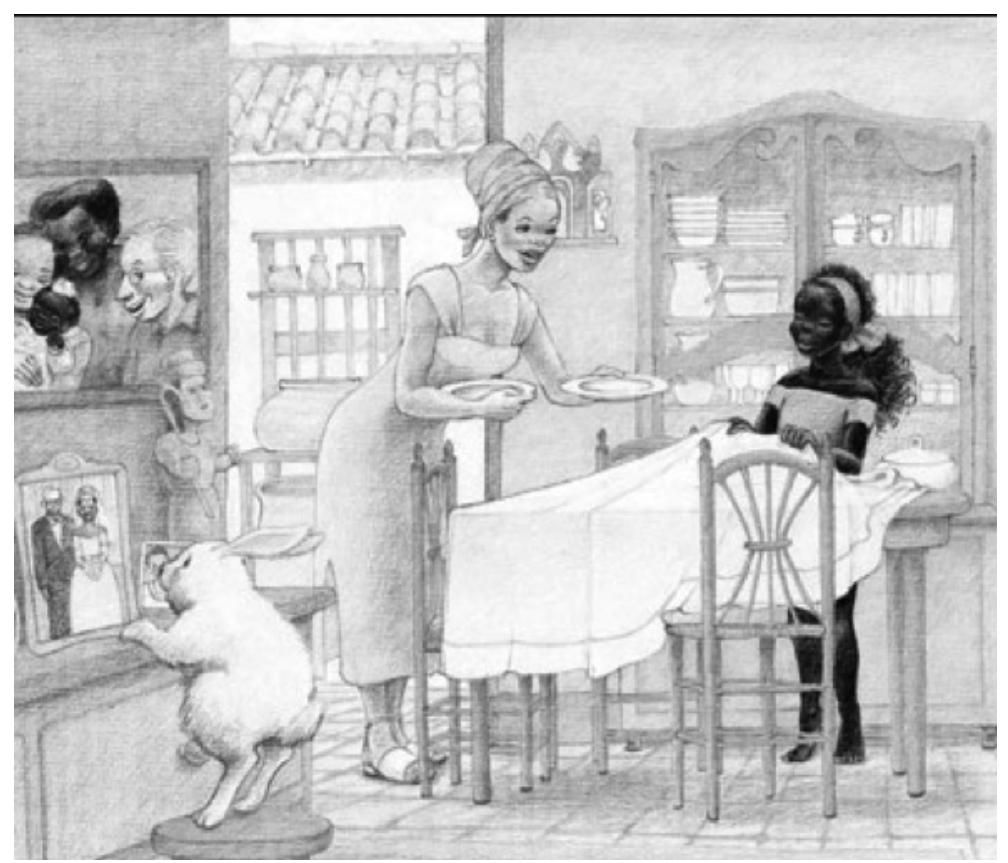


En estas ilustraciones, que corresponden al cuento de Niña Bonita, se puede ver cómo la familia es un eje importante en el desarrollo de la narrativa pues es precisamente a partir de ella desde las cuales la niña logra su autoidentificación. El ambiente que se identifica en las imágenes da una sensación de calidez pues se percibe un vínculo positivo entre la madre y su hija, contribuyendo a establecer que las relaciones familiares son fundamentales en estos procesos de lograr la propia valoración y entendimiento de la diversidad.

Sin embargo, es curioso que no en todas las ilustraciones que se presentan en el cuento se pueden identificar los rasgos del resto de la niña, sino que en cambio se rescatan otros elementos de la historia como la familia que forma el amigo de la protagonista, es decir el conejo blanco y además se resaltan otros colores para crear más contraste y dinamismo en la imagen.

Imagen 3. La muñeca negra. Por Mary Grueso (2011).

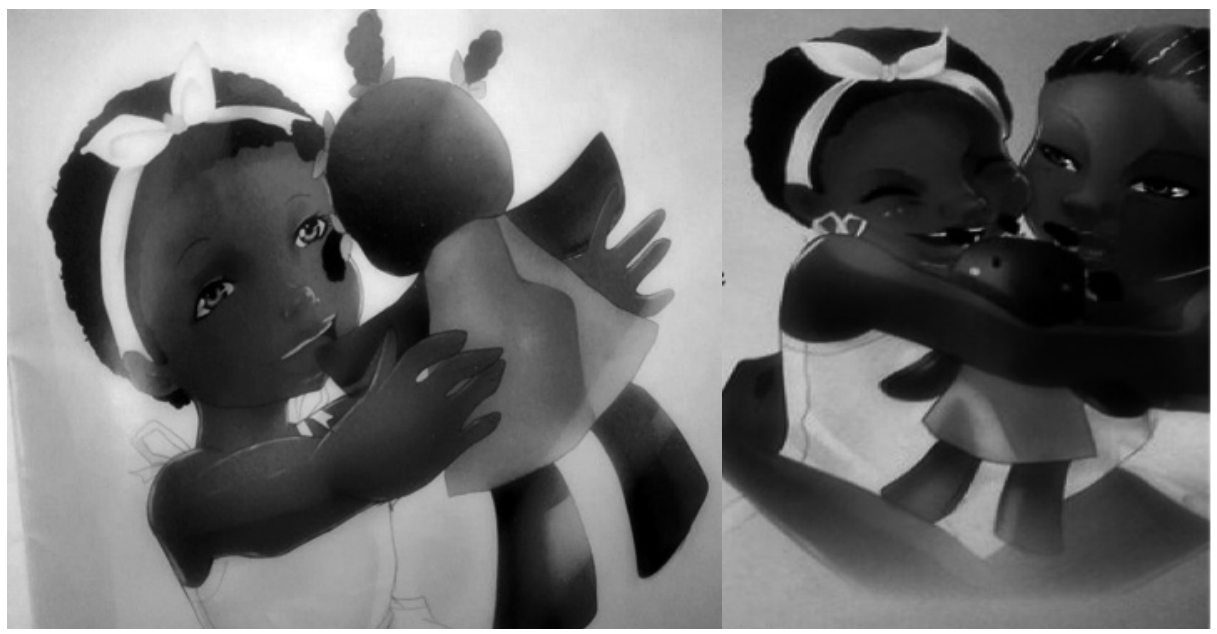

En el cuento La muñeca negra se resaltan los rasgos de los protagonistas, puesto que en todas las ilustraciones es posible ver claramente las características físicas y del entorno en el que se desenvuelve la historia. Entre ellas están el cabello de chacarrás, la vestimenta de un clima cálido como el que se presenta en el Pacífico, la hoja de plátano propia de productos de la región y los paisajes que permiten resaltar 
los componentes significativos del territorio para hacer una apropiación del mismo, entre estos se encuentra la playa, las palmeras, las casas de madera entre otros.

Y por último, en las ilustraciones se resalta la fuerte relación que hay entre la niña y su madre, pues por otro lado, su padre es quien le niega la posibilidad de poder encontrar una muñeca que sea de su color.

En conclusión los dos cuentos son una fuente importante de un nuevo interés en tratar la diversidad desde los más pequeños, tema que debería ser principal en las agendas educativas de Latinoamérica, atendiendo a la multiculturalidad del continente.

Además hay que resaltar el papel que juegan las mujeres en los dos cuentos como productoras de narraciones que avalan a promover un respeto por lo ancestral más allá de las relaciones de dominación que se pueden crear entre personas con un mismo vínculo.

\section{Referencias}

De Friedemann, N. S., \& Arocha, J. (1988). De sol a sol: génesis, transformación y presencia de los negros en Colombia. Planeta. Recuperado de: http:// ecaths1.s3.amazonaws.com/afropacifico/De.Sol.a.Sol.380504150.pdf

Grueso Romero, M. (2011). La muñeca negra. Bogotá: Apidama.

Jaramillo Hincapié, J. (2014). Una cátedra electiva de estudios afrocolombianos y afrolatinoamericanos desde una facultad de comunicación social para la paz. GT1: Comunicación Intercultural y Folkcomunicación Disponible en: http://congreso.pucp.edu.pe/alaic2014/wpcontent/uploads/2013/09/ Ponencia-Jorge-Iv\%C3\%A1n-Jaramillo-Colombia-GT1__2_.pdf

Machado, A., Faría, R. y Iribarren, E. (1996). Niña Bonita. Brooklyn, N.Y.: Kane/Miller Book Publishers. Recuperado de: https://es.scribd.com/ doc/32297851/nina-bonita

Van Dijk, T. (1980). Estructuras y funciones del discurso. Una introducción interdisciplinaria a la lingǘstica del texto y a los estudios del discurso. México: Siglo Veintiuno.

Zapata Olivella, M. (1997). La rebelión de los genes. Bogotá, Colombia: Altamir. 
